\title{
Incentives for Green and Low-Carbon Technological Innovation of Enterprises Under Environmental Regulation: From the Perspective of Evolutionary Game
}

\author{
Lei Chen, Xin Bai, Bi Chen and Jingjing Wang* \\ Chongqingfuling Electric Power Industrial Co., Ltd., Chongqing, China
}

Encouraging enterprises to adopt green and low-carbon technological innovation is an important measure to cope with climate change and achieve low-carbon economic development. As the main stakeholders of green and low-carbon technological innovation of enterprises, what measures should the government and the public take

OPEN ACCESS

Edited by:

Xin Yao,

Xiamen University, China

Reviewed by:

Ailun Wang,

Southwestern University of

Finance and Economics, China

Houyin Long,

Fuzhou University, China

*Correspondence:

Jingjing Wang

jjwang_work@126.com

Specialty section:

This article was submitted to Sustainable Energy Systems and

Policies,

a section of the journal Frontiers in Energy Research

Received: 12 October 2021 Accepted: 09 November 2021

Published: 03 January 2022

Citation:

Chen L, Bai X, Chen B and Wang J (2022) Incentives for Green and Low-

Carbon Technological Innovation of

Enterprises Under Environmental Regulation: From the Perspective of

Evolutionary Game.

Front. Energy Res. 9:793667. doi: 10.3389/fenrg.2021.793667 to encourage green and low-carbon technological innovation of enterprises has become one of the focuses of research. This study constructs a tripartite evolutionary game model among the government, the public, and enterprises and then obtains the evolutionary stability strategy by analyzing the replication dynamic equation of each subject. Numerical simulation is made on the evolution path of the game under different enforcement intensities of environmental regulation means. The result shows that pollution tax, lowcarbon technology innovation subsidy, and environmental protection publicity and guidance are three environmental regulation means to effectively stimulate enterprises' green and low-carbon technology innovation. And moderate pollution tax, low-intensity publicity of public environmental protection, and high innovation incentive compensation have the highest incentive efficiency for enterprises' green and low-carbon technological innovation. Targeted suggestions for promoting green and low-carbon technological innovation of enterprises are put forward in the end.

\begin{abstract}
Keywords: environmental regulation, green and low-carbon technological innovation, evolutionary game, numerical simulation, replicator dynamics equation
\end{abstract}

\section{INTRODUCTION}

The environmental impact caused by the excessive exploitation and utilization of energy, such as climate change, has posed a great challenge to the survival and development of human beings (Gaffney and Steffen, 2017; Tian et al., 2019). In the past 40 years, the frequency and intensity of extreme weather and natural disasters caused by global climate change have increased significantly, posing increasingly severe challenges to human survival and development. It has become a consensus of the international community to reduce emissions and develop a low-carbon economy to cope with global climate change. As the world's largest emitter of carbon dioxide, China's emissions status and its commitment to reducing emissions have attracted a lot of attention from the international community (Zhang et al., 2012; Cheng et al., 2021). At the General Debate of the 75th Session of the 
United Nations General Assembly, President Xi Jinping pledged that China will strive to reach the peak of $\mathrm{CO}_{2}$ emissions by 2030 and strive to be carbon neutral by 2060. Promoting green development through technological innovation is the inevitable choice to achieve the goal of carbon neutrality. To achieve the goal of energy conservation and emission reduction and promote the development of a low-carbon economy, vigorously developing energy technology and carrying out green and low-carbon technological innovation are the fundamental ways (Lutz et al., 2005; Wu et al., 2005; Smulders et al., 2014; Cheng and Yao, 2021). Green and low-carbon technological innovation is conducive to improving the overall utilization efficiency of resources and reducing resource consumption (Jia et al., 2018; Lin and Zhu, 2019). It is a key means to control climate problems, promote the construction of low-carbon cities, and realize lowcarbon economy and sustainable development mode (Teixidó et al., 2019; Song et al., 2020a). It is also an effective way to promote China's transformation from a high-carbon economy characterized by "high energy consumption, high emission, and high pollution" to a low-carbon economy which features "low energy consumption, low emission, and low pollution" (Zhang and Zhang, 2019; Du et al., 2021).

In the composition of China's carbon emissions, corporate carbon emissions have been high and occupy a large proportion. Therefore, under the vision of "reaching carbon peak by 2030 and being carbon neutral by 2060," enterprises will gradually become an increasingly important subject of action and responsibility in addressing climate change and achieving low-carbon development. As the main body of innovation, enterprises must be supported by green and low-carbon technology to achieve carbon reduction and pollution reduction and fulfill their social responsibilities. However, high initial investment costs and the dependence of the current technology path are seriously restricting the promotion of low-carbon technology innovation. Moreover, the public's awareness of low-carbon products is relatively low, and the concept of low-carbon in society is not popular enough, which greatly slows down the process of low-carbon technological innovation of enterprises and reduces enterprises' enthusiasm for low-carbon technological innovation. Therefore, green and low-carbon technological innovation is difficult to form spontaneously. The lack of enterprises' motivation for low-carbon technological innovation requires external environmental regulation to provide punishment or incentive mechanisms (Song et al., 2020b). Therefore, reasonable environmental regulation policies can make up for the contrast between the cost and benefit of enterprises' low-carbon technological innovation and promote the pace of enterprises' implementation of low-carbon technological innovation (Song et al., 2021). In addition, public consumers are the main demanders in the low-carbon product market, whose preference for low-carbon products directly affects the production decisions of enterprises (Khan et al., 2021). The government's publicity and guidance for low-carbon technological innovation can effectively stimulate the public's demand for low-carbon products, thus encouraging enterprises to carry out green and low-carbon technological innovation. With the worsening of environmental pollution, the public's requirements for enterprises' green and low-carbon technological innovation have intensified, and the supervision has also been strengthened.

Thus, in the context of low-carbon economy and sustainable development, it is of great significance to explore how government incentives and punishment policies and the public's consumer supervision behavior affect enterprises' lowcarbon technological innovation, forming a benign interaction between the government, the public, and enterprises to stimulate enterprises' innovation behavior. However, there are few studies that unify the three in one system to study the common environmental responsibility, interest relationship, and mutual influence of the three parties. Based on this, this study aims to explore how to get rid of traditional non-environmental protection technologies and encourage enterprises to carry out green and low-carbon technological innovation under the participation of the public and the environmental regulation of the government. The marginal contribution of this study is as follows: 1) establish a game model with the government, the public (consumers), and enterprises as the three participants, and study the strategic choices of the three stakeholders; 2) find out the equilibrium point by solving the replicator dynamics equation and analyze its asymptotic stability; and 3) the evolutionary game model is simulated by a MATLAB numerical simulation analysis tool so as to find the path to encourage enterprises to choose the green and low-carbon innovation mode.

The remainder of this study is structured as follows: Literature Review section presents a review of the related literature, followed by the model hypothesis and construction in Model Hypothesis and Construction section. In Model Analysis section, we analyze the stability of the equilibrium point in the evolutionary game. Numerical Simulation Analysis section presents the numerical simulation results of the game model. Conclusions and policy implications are presented in Conclusion section.

\section{LITERATURE REVIEW}

With the challenge posed by environmental pollution and global warming, the development of green, low-carbon, and circular economy becomes matters of great concern for the academic community (Lai et al., 2016). The technological progress needed to develop a low-carbon economy is green and low-carbon technological innovation (Li et al., 2021). As an important carrier for the development of low-carbon economy, enterprises are not only the main body of carbon emissions but also the main undertaker of environmental protection and low-carbon emission reduction. Under the strict requirements of ecological environment, green and low-carbon technological innovation, as the strategic direction of enterprises, is the core of enterprise production and operation and is crucial to the improvement of their competitiveness, their ability of market survival, and sustainable development (Bi et al., 2016). Enterprises need to make trade-off between traditional technology and green low-carbon technology innovation. However, due to the large upfront investment cost of green and low-carbon technological innovation and the large 
uncertainty of the later income, enterprises are not strong in their willingness to take the initiative to conduct green and low-carbon technological innovation ( $\mathrm{Qu}$ et al., 2019). Based on this, the government needs to take measures to motivate enterprises' green and low-carbon technological innovation effectively.

At present, there are abundant research studies on government regulation, government intervention, and enterprise innovation. Bi et al. (2016) used DEA and Tobit two-stage method under the framework of the global value chain to analyze the main factors affecting manufacturing enterprises' low-carbon technological innovation and found that government regulation was the main driving factor. Based on a quasi-natural experiment, Chakraborty and Chatterjee (2017) assessed the impact of environmental regulation policies on green innovation activities of Indian enterprises, finding that environmental regulation indirectly triggered green technology innovation of upstream firms. Using the BarabasiAlbert model, Zhang L. et al. (2019) respectively studied the impact of government environmental regulation measures such as carbon trading, environmental taxation, and innovation subsidies on green technology innovation and diffusion of Chinese manufacturing enterprises. Based on the data of environmental regulation (ER) and green technology innovation (GTI) of 30 provinces in China from 2007 to 2016, Guo et al. (2019) found that environmental regulation has a certain promotion effect on enterprises' green technology innovation. Lyu et al. (2020) used the DID model to study the impact of carbon emission trading on low-carbon technological innovation of enterprises. Pan et al. (2021) found that the Two Control Zone (TCZ) environmental regulation policy in China had effectively promoted enterprises' cleaner production technology innovation.

However, there is still no consensus on the direction of the impact of government environmental regulations on green and low-carbon technological innovation of enterprises. Many scholars believe that the adoption of environmental regulation means by the government can effectively encourage enterprises to conduct green and low-carbon technological innovation (Brunnermeier and Cohen, 2003; Lin and Yang, 2011; Dietrich and Chen, 2018; Liang et al., 2019). Some scholars, such as supporters of the Porter Hypothesis, believe that environmental regulation measures have to some extent inhibited enterprises' green and low-carbon technological innovation behavior (Chintrakarn, 2008). Besides, there are also opinions that the direction of influence between the two is uncertain ( $\mathrm{Hu}$ et al., 2008). In addition to the government's environmental regulations, enterprises' green and low-carbon technological innovation behavior will also be affected by many internal and external driving factors. External factors include the public opinion pressure (Hu et al., 2008), the demand of multinational corporations and consumers for lowcarbon products (Kammerer, 2009; Fan and Dong, 2018), consumers' environmental awareness (Wang and Zheng, 2019), stakeholder pressure (Olusegun et al., 2014; Jiang et al., 2018), and intra- and inter-industry competitive pressure (Cao et al., 2012). Internal factors include the enterprise's innovation capabilities (Jiang et al., 2018) and the enterprise's pursuit of economic interests (Klassen and McLaughlin, 1996; Xia et al., 2015).

Many scholars have applied the evolutionary game method to study the relationship between government environmental regulations and enterprises' green and low-carbon behaviors. For example, with the construction of a mixed-strategy evolutionary game model between the government and enterprises, Wang et al. (2011) believe that the government can encourage enterprises to carry out low-carbon production by adopting the environmental regulation means of dynamic punishment. Wu et al. (2017) constructed an evolutionary game model between the government and enterprises in the context of low-carbon economy and studied the incentive effect of government's environmental regulation policies on enterprises' low-carbon production. Fan et al. (2017) constructed an evolutionary game model between the government and enterprises with supervision and without supervision, respectively, and studied the optimal regulatory strategy of the government for enterprises' low-carbon subsidies as well as the regulatory efficiency and stability. Taking the objective functions of enterprises and governments in three different scenarios into consideration, Mahmoudi and Rasti-Barzoki (2018) established an evolutionary game model between the government and enterprises and analyzed the impact of government environmental regulation policies on enterprises' low-carbon production, carbon emissions, and competitiveness, respectively.

In addition, the evolutionary game model is often used to study the incentive effect of government environmental regulations on enterprises' green and low-carbon technological innovation. By establishing a game model between government regulators and enterprises, Krass et al. (2013) found that the two environmental regulation means, cost subsidy and tax punishment, could effectively mobilize enterprises to conduct green and low-carbon technological innovation and choose the low-carbon production mode. Huang et al. (2013) studied the influence of government subsidies and centralized control without subsidies on enterprises' low-carbon technological innovation, respectively, in a duopoly setting and found that the incentive scheme with the centralized control with no subsidy is more effective in stimulating enterprises' low-carbon technological innovation. By analyzing the equilibrium solution of the tripartite evolutionary game model of the government, enterprises, and consumers, $\mathrm{Xu}$ and Lv (2014) pointed out that the government's environmental regulation measures effectively stimulated enterprises' decision-making of green and low-carbon technological innovation. Liu et al. (2017) deduced the equilibrium strategy of the evolutionary game between the government and automobile manufacturers and found that the government's dynamic tax and static subsidies are effective incentive means. Under the framework of the evolutionary game, Jiao et al. (2017) compared the incentive effects of carbon quota, carbon trading price, and government supervision cost on enterprises' adoption of green and lowcarbon technology innovation. Chen and $\mathrm{Hu}$ (2018) obtained the optimal carbon tax and subsidy mechanism by analyzing the stable strategy solution of the evolutionary game between the government and manufacturing enterprises under different 
conditions. Cheng et al. (2021) found that the government's compensation method for enterprises' innovation behaviors, such as transfer payment and tax credit, can effectively encourage enterprises to turn to green and low-carbon technology innovation.

With the application of different methods such as empirical analysis, theoretical research, and simulation model, the aforementioned research studies deeply explore the influence of government environmental regulation means and other factors on enterprises' green and low-carbon technological innovation. However, most of the existing studies only focus on the mutual influence between the government or public consumers and enterprises, without unifying the three parties into a system to study the common environmental responsibility, interest relationship, and mutual influence of the three. As a public good, the environment connects the interests of the government, enterprises, and public consumers in complex social relations. Therefore, the profit loss of any party will affect the innovation behavior of enterprises' low-carbon technology. Based on this, this study attempts to construct a tripartite evolutionary game model including the government, enterprises, and public consumers using the evolutionary game method of bounded rationality hypothesis. Through evolutionary game stability analysis and numerical simulation, this article discusses the incentive effect of different regulation means and enforcement intensity on enterprises' low-carbon technological innovation and strives to provide a useful reference for enterprises' low-carbon technological innovation decisionmaking and government's environmental regulation policy formulation in the context of low carbon.

\section{MODEL HYPOTHESIS AND CONSTRUCTION}

\section{Stakeholder Analysis}

Under the common vision of "carbon neutrality," whether an enterprise conducts green and low-carbon technological innovation is not only a strategic issue related to the gain and loss of its own interests but also a common proposition closely related to the interests of the country, the public, and every individual. Therefore, as the main body of green and low-carbon technology innovation, enterprises' decisions and behaviors are not only driven by their own interests but also subject to the supervision and influence of the public and the government.

From the perspective of economics, the behavior of enterprises conducting the green and low-carbon technological innovation mode has strong positive externalities. Since most of the production and operation activities of enterprises are based on the profit maximization, the problems of "prisoner's dilemma" and "tragedy of the commons" are common to arise. With the green and low-carbon technological innovation, the natural resources, including traditional fossil energy, consumed by enterprises due to production and operation activities will be greatly reduced, and thus, the environmental pollution caused by enterprise activities will be reduced. Such "energy conservation and environmental protection" results bring much more benefits to the society than enterprises' own interests, while enterprises need to pay a high cost for their low-carbon innovation behavior. On the contrary, if the enterprise chooses to maintain the traditional technology, instead of conducting green and lowcarbon technology innovation, the enterprise will save the corresponding innovation cost while the society will pay more cost for the environmental pollution caused by the production using traditional technology. This is a typical example where the private cost is far less than the social cost (Cheng et al., 2017; Miao et al., 2019).

As a national environmental manager and supervisor, the government's environmental regulation means will indirectly affect enterprises' low-carbon innovation behavior (Song et al., 2020a; Ouyang et al., 2020; Zhuge et al., 2020). On the one hand, the higher the consumers' awareness of green and low-carbon, the greater is their preference for green and low-carbon products (Chen et al., 2018). The government's vigorous publicity and popularization of green and low-carbon will improve the social view of environmental protection and green consumption and also improve the market acceptance and recognition of green and low-carbon products (Zhu et al., 2013; Jan et al., 2019). It will make the traditional high energy consumption, high pollution, non-environmental protection products gradually phased out by the market, thus forcing enterprises to turn to the green and lowcarbon technology innovation mode. At the same time, by the means of propaganda and guidance, the government can encourage the public to actively supervise enterprises' lowcarbon technological innovation behavior (Chen et al., 2018; Fan et al., 2019). On the other hand, measures such as pollution tax or green subsidy adopted by the government will directly affect the final profit of enterprises, which internalizes the external benefits of enterprises' low-carbon technological innovation and strengthens the motivation of enterprises to conduct green and low-carbon technological innovation (Brav et al., 2018; Song et al., 2020b).

From the perspective of the product market, as the last link of consumer behavior, green consumption can make green production activities make a real difference and achieve sustainable development (Zhang Y. et al., 2019). Public consumers' satisfaction and acceptance of enterprise products will directly affect the production activities of enterprises. Enterprises are motivated to develop green products that adopt sustainable innovation or materials if environmental sustainability prevails among consumers (Chang and Zhang, 2019). Moreover, if the traditional non-environmental protection production activities of enterprises cause the environmental pollution, consumers, as the victims of pollution, will spontaneously supervise the production behavior of enterprises and adjust their consumption decisions accordingly, which will affect the profits of enterprises (Kammerer, 2009; Lin et al., 2013). Therefore, the public can "vote" for enterprises' green and low-carbon technological innovation through their consumption behavior.

To sum up, enterprises' decision on whether to conduct green and low-carbon technological innovation has a great influence on their own profit, production efficiency, energy efficiency, and their social image. And it will also have an impact on the natural 


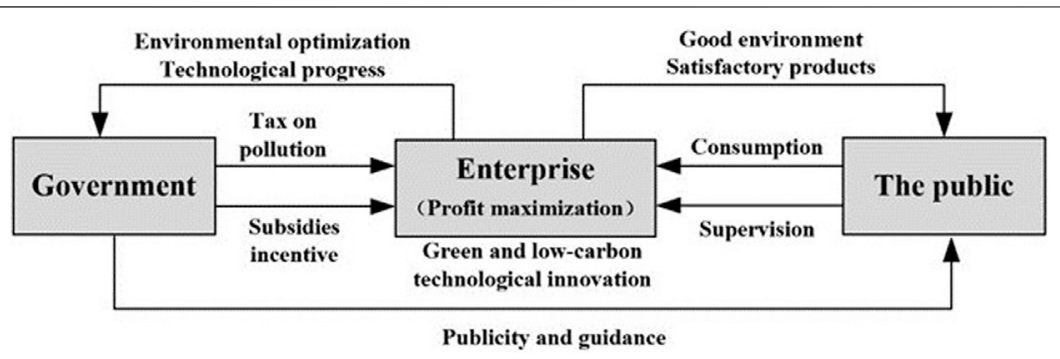

FIGURE 1| Relationship between the stakeholders.

environment and then affect the interests of the government and the public, thus causing the government's regulation and social supervision. Moreover, when making the strategic choice of whether to adopt the green and low-carbon technology innovation mode, enterprises will not only take their needs of interest into account but also the consumption preference of the public, the social consciousness of environmental protection, the social acceptance of innovative products, and the requirements of government policies. Therefore, the interests of the enterprise, the government, and the public are mutually restricted and influenced. To be more intuitive, we use Figure 1 to simply represent the interest relationship between the three.

\section{Hypothesis}

As an important economic analytical tool, the game theory has been widely applied in various fields to explain some social phenomena (Su et al., 2018a; Su et al., 2018b; Ma and Sun, 2018; Xie et al., 2018). The evolutionary game theory studies the changing trend and stability of the proportion of specific strategies adopted by game groups based on the learning ability and bounded rationality of game subjects (Smith, 1976; Friedman, 1998). Different from traditional games that emphasize static equilibrium, evolutionary games emphasize the dynamic process to reach system equilibrium as well as the overall evolution result and stability of the system. The selection process of the green and low-carbon technology innovation mode of enterprises is the result of enterprises' continuous learning and adjustment of their own strategies in response to the different interest demands of the three parties in the system composed of the government, the public, and the enterprise itself, which is consistent with the evolutionary game theory. Therefore, in order to find the effective ways to encourage enterprises to conduct green and low-carbon technology innovation mode, this study constructs an evolutionary game model that includes the government, the public (consumers), and enterprises. We assume that the strategies of the government are \{regulation, no regulation\}. The strategies of the public consumers are \{Supervision, No supervision\}, while the strategies of enterprises are \{conduct green and low-carbon technological innovation, adopt traditional techniques\}. We first make the following assumptions:

Hypothesis 1: Participating subjects. In this model, the government, the public (consumers), and enterprises are considered a system without considering other constraints.
All of them have bounded rationality and certain learning ability. They can form their own strategies and make decisions in response to the actual situation. And they can also adjust their strategies in the process of continuous learning and trial and error to reach an equilibrium state. In the model, $x(t)$, $y(t)$, and $z(t)$ represent the probability that the government chooses an environmental regulation strategy, social consumers choose the supervision strategy, and enterprises choose conducting green and low-carbon technology innovation, respectively, where $t$ presents the time and $x(t), y(t), z(t) \in[0,1]$.

Hypothesis 2: Regulatory policies. Taxing on pollution, subsidizing and incentivizing green and low-carbon technological innovation (including innovative product price subsidy and innovative cost subsidy), and conducting social propaganda and guidance are the four means for the government to conduct environmental regulation on enterprises. $\alpha E, \beta P, \gamma T$, and $\eta K$ are, respectively, used to represent the cost of these four environmental regulation means, where $\alpha$ represents the enforcement intensity of emission tax levy; $\beta$ and $\gamma$ represent the proportion of subsidies for low-carbon technology innovation products and for low-carbon technology costs, respectively; and $\eta$ represents the implementation intensity of work of environmental propaganda and guidance.

Hypothesis 3: The payoffs of each entity. The profit obtained by the enterprise using traditional technology for production is $R$. If an enterprise still uses traditional technology to carry out polluting production activities under the supervision of the public, it will lose $C_{L}$ due to the public's consumption preference. After adopting the green and low-carbon technology innovation mode, enterprises gain incremental benefits $\Delta R$. Specifically, under the four strategies of (regulation, supervision), (regulation, no supervision), (no regulation, supervision), and (no regulation, no supervision), the incremental benefits of enterprises are $\Delta R_{1}, \Delta R_{2}, \Delta R_{3}$, and 0 , respectively. In addition, the government finds enterprises' deceptive rent-seeking behavior for the purpose of obtaining innovation subsidies with a certain probability $\lambda$ and punishes such behavior according to the standard of pollution tax. The cost of enterprises' green and low-carbon technology innovation is $C_{I}$. Meanwhile, the environmental benefits brought to the government and the public are $R_{G}$ and $R_{s}$, respectively. On the contrary, if enterprises continue to use traditional 
TABLE 1 | Parameter descriptions.

\begin{tabular}{|c|c|c|}
\hline Stakeholder & Parameters & Descriptions \\
\hline \multirow[t]{8}{*}{ Government } & $x$ & The probability that the government chooses an environmental regulation strategy \\
\hline & $R_{G}$ & The environmental benefits brought to the government if enterprises conduct green and low-carbon technology innovation \\
\hline & $L_{G}$ & The losses that governments will suffer if companies choose to use traditional technologies \\
\hline & $\alpha E$ & Tax on pollution, where $\alpha$ represents the enforcement intensity of emission tax levy \\
\hline & $\beta P$ & $\begin{array}{l}\text { Subsidies for low-carbon technology innovation products, where } \beta \text { represent the proportion of subsidies for low-carbon } \\
\text { technology innovation products }\end{array}$ \\
\hline & $\gamma T$ & Subsidies for low-carbon technology costs, where $\gamma$ represent the proportion of subsidies for low-carbon technology costs \\
\hline & $\eta K$ & $\begin{array}{l}\text { Costs for conducting social propaganda and guidance, where } \eta \text { represents the implementation intensity of work of } \\
\text { environmental propaganda and guidance }\end{array}$ \\
\hline & $\lambda$ & $\begin{array}{l}\text { The probability that the government finds enterprises' deceptive rent-seeking behaviors for the purpose of obtaining } \\
\text { innovation subsidies }\end{array}$ \\
\hline \multirow[t]{4}{*}{ Consumers } & $R_{S}$ & The environmental benefits brought to the consumers if enterprises conduct green and low-carbon technology innovation \\
\hline & $L_{s}$ & The losses that consumers will suffer if companies choose to use traditional technologies \\
\hline & 1 & $\begin{array}{l}\text { The extra rewards from the government if the public has a high degree of preference and demand for enterprises' green and } \\
\text { low-carbon technology innovation products }\end{array}$ \\
\hline & $C_{s}$ & The cost of public supervision \\
\hline \multirow[t]{6}{*}{ Enterprises } & $R$ & The profit obtained by the enterprise using traditional technology for production \\
\hline & $C_{L}$ & $\begin{array}{l}\text { The losses that the enterprise will suffer if traditional technology is used to carry out polluting production activities under the } \\
\text { supervision of the public }\end{array}$ \\
\hline & $\Delta R_{1}$ & $\begin{array}{l}\text { The incremental benefits of enterprises after adopting the green and low-carbon technology innovation mode under the } \\
\text { strategy profile of (regulation, supervision) }\end{array}$ \\
\hline & $\Delta R_{2}$ & $\begin{array}{l}\text { The incremental benefits of enterprises after adopting the green and low-carbon technology innovation mode under the } \\
\text { strategy profile of (regulation, no supervision) }\end{array}$ \\
\hline & $\Delta R_{3}$ & $\begin{array}{l}\text { The incremental benefits of enterprises after adopting the green and low-carbon technology innovation mode under the } \\
\text { strategy profile of (no regulation, supervision) }\end{array}$ \\
\hline & $C_{l}$ & The cost of enterprises' green and low-carbon technology \\
\hline
\end{tabular}

TABLE 2 | Tripartite evolutionary game payment matrix.

\begin{tabular}{|c|c|c|}
\hline & \multicolumn{2}{|c|}{ Regulation (x) } \\
\hline & Supervision (y) & No supervision $(1-y)$ \\
\hline Conduct green and low-carbon technological innovation (z) & $\begin{array}{l}R_{G}+\lambda \alpha E-\beta P-\gamma T-\eta K-I \\
R_{S}+I-C_{S} \\
R+\Delta R_{1}-C_{l}+\beta P+\gamma T-\lambda \alpha E\end{array}$ & $\begin{array}{l}R_{G}+\lambda \alpha E-\beta P-\gamma T-\eta K \\
R_{S} \\
R+\Delta R_{2}-C_{l}+\beta P+\gamma T-\lambda \alpha E\end{array}$ \\
\hline \multirow[t]{3}{*}{ Adopt traditional techniques $(1-z)$} & $\begin{array}{l}\alpha E-\eta K-I-L_{G} \\
I-C_{S}-L_{S} \\
R-\alpha E-C_{L}\end{array}$ & $\begin{array}{l}\alpha E-\eta K-L_{G} \\
-L_{S} \\
R-\alpha E\end{array}$ \\
\hline & \multicolumn{2}{|c|}{ No regulation $(1-\mathbf{x})$} \\
\hline & Supervision (y) & No supervision $(1-y)$ \\
\hline Conduct green and low-carbon technological innovation ( $z$ ) & $\begin{array}{l}R_{G}-1 \\
R_{S}+1-C_{S} \\
R+\Delta R_{3}-C_{l}\end{array}$ & $\begin{array}{l}R_{G} \\
R_{S} \\
R-C_{l}\end{array}$ \\
\hline Adopt traditional techniques $(1-z)$ & $\begin{array}{l}-L_{G}-I \\
I-L_{S}-C_{S} \\
R-C_{L}\end{array}$ & $\begin{array}{l}-L_{G} \\
-L_{S} \\
R\end{array}$ \\
\hline
\end{tabular}

Note: From the top to bottom are the payoffs of government, the public, and enterprises, respectively.

production technology, the possibility of pollution discharge will increase, and the government and the public will suffer losses $L_{G}$ and $L_{s}$, respectively, due to the environmental pollution. Besides, if the public has a high degree of preference and demand for enterprises' green and low-carbon technology innovation products, and "vote" for enterprises' low-carbon technology innovation by consumption behaviors, then it is considered that public consumers have effectively supervised enterprises' low-carbon technology innovation behavior. And then, consumers will get extra rewards from the government $I$. The cost of public supervision is $C_{s}$. The corresponding parameters are given in Table $\mathbf{1}$. 


\section{Evolutionary Game Model Construction}

Based on the aforementioned assumptions that the payoff of the participants is the difference between profit and cost (Hofbauer and Sandholm, 2007), this study constructs an evolutionary game model with the government, the public, and enterprises as the main participants. The payment matrix of the tripartite evolutionary game is given in Table 2 .

\section{MODEL ANALYSIS}

\section{The Strategy Stability Analysis of Each Party}

Due to the information asymmetry between the government, enterprises, and the public under environmental regulation, the three parties will judge the strategies of other players based on historical experience and adjust their own strategies in the process of continuous learning and trial and error. Therefore, in the process of dynamic adjustment of their own strategies, the government, enterprises, and the public show a dynamic replication process in the evolutionary game. Based on the payment matrix, we calculate the replication dynamic equation of the government, enterprises, and the public, respectively, and analyze the strategic stability of each entity.

\section{Analysis on the Stability of Government's Strategy}

According to the payment matrix, the expected revenue $u_{x}$ when the government chooses the strategy of "regulation," the expected revenue $u_{1-x}$ when the government chooses "no regulation," and the average expected revenue $\bar{u}_{1}$ are shown, respectively, in Eq. 1:

$$
\begin{aligned}
u_{x}= & y z\left(R_{G}+\lambda \alpha E-\beta P-\gamma T-\eta K-I\right)+(1-y) z\left(R_{G}+\lambda \alpha E\right. \\
& -\beta P-\gamma T-\eta K)+y(1-z)\left(\alpha E-\eta K-I-L_{G}\right) \\
& +(1-y)(1-z)\left(\alpha E-\eta K-L_{G}\right) \\
= & \alpha E(1-z+z \lambda)+z\left(R_{G}+L_{G}-\beta P-\gamma T\right) \\
& +\left(-L_{G}-\eta K-y I\right) \\
u_{1-x}= & y z\left(R_{G}-I\right)+(1-y) z R_{G}+y\left((1-z)\left(-L_{G}-I\right)\right. \\
& +(1-y)(1-z)\left(-L_{G}\right) \\
= & z R_{G}-(1-z) L_{G}-y I \\
\bar{u}_{1}= & x u_{x}+(1-x) u_{1-x} .
\end{aligned}
$$

The replicator dynamic equation of environmental regulation by the government is shown in Eq. 2:

$$
\begin{aligned}
F(x) & =\frac{d x}{d t}=x\left(u_{x}-\bar{u}_{1}\right) \\
& =x(1-x)[\alpha E(1-z+z \lambda)+z(-\beta P-\gamma T)-\eta K] .
\end{aligned}
$$

The first derivative of $F(x)$ and the defined $G(z)$ are, respectively, shown in Eqs 3, 4:

$$
\begin{gathered}
\frac{d(F(x))}{d x}=(1-2 x)[\alpha E(1-z+z \lambda)+z(-\beta P-\gamma T)-\eta K] \\
G(z)=\alpha E(1-z+z \lambda)+z(-\beta P-\gamma T)-\eta K .
\end{gathered}
$$

According to the implicit theorem of differential equations, $\mathrm{F}(x)=0$ and $d(F(x)) / d x<0$ are the stability condition of the government's adoption of regulation. Since $\partial G(z) / \partial z=-(1-\lambda+\beta P+\gamma T)<0, \quad G(z) \quad$ is a decreasing function of $z$. Therefore, when $z=(\alpha E-\eta K) /(1-\lambda+\beta P+\gamma T)=z *, G(z)=0$ is derived, so $d(F(x)) / d x \equiv 0$ and $F(x) \equiv 0$. Then the stable state can be achieved at all values of $x$. When $z<z^{*}$, we have $G(z)>0$ and $d(F(x)) /\left.d x\right|_{x=1}<0$. The government's strategy is stable at $x=1$. Otherwise, $x=0$ is the evolutionary stable strategy. Thus, the phase diagram of the government's stability evolution is related to the curve $(1-2 x)[\alpha E(1-z+z \lambda)+z(-\beta P-\gamma T)-\eta K]$.

\section{Analysis on the Strategic Stability of the Public}

The expected payoff $u_{y}$ when the public adopts the supervision strategy, the expected payoff when the strategy of no supervision is adopted, and the average expected payoff $\bar{u}_{2}$ are, respectively, shown in Eq. 5:

$$
\begin{aligned}
u_{y}= & x z\left(R_{s}+I-C_{S}\right)+x(1-z)\left(I-C_{S}-L_{S}\right) \\
& +(1-x) z\left(R_{s}+I-C_{S}\right)+(1-x)(1-z)\left(I-L_{s}-C_{S}\right) \\
= & z R_{s}+I-C_{S}-(1-z) L_{S} \\
u_{1-y}= & x z R_{s}+x(1-z)\left(-L_{S}\right)+(1-x) z R_{s} \\
& \quad+(1-x)(1-z)\left(-L_{s}\right) \\
= & z R_{s}-(1-z) L_{S} \\
\bar{u}_{2}= & y u_{y}+(1-y) u_{1-y} .
\end{aligned}
$$

According to Eq. 5, the replicator dynamic equation of the supervision strategy adopted by the public and its first derivative can be, respectively, written as Eqs 6, 7:

$$
\begin{gathered}
F(y)=\frac{d y}{d t}=y\left(u_{y}-\bar{u}_{2}\right)=y(1-y)\left(I-C_{S}\right) \\
\frac{d(F(y))}{d y}=(1-2 y)\left(I-C_{S}\right) .
\end{gathered}
$$

According to the implicit theorem of differential equations, when $\mathrm{F}(y)=0$ and $d(F(y)) / d y<0$, the probability of social public choice of supervision strategy is in a stable state. Therefore, the quantitative relationship between the government's incentive to the public Iand the cost of public supervision $C_{S}$ determines the strategy evolution of public. To be specific, when $I=C_{S}, \mathrm{~F}(y) \equiv 0$, and $d(F(y)) / d y \equiv 0$ are obtained, the strategy of supervision is in stable state with all the values of $y$. When $I>C_{S}$, we can derive $d(F(y)) /\left.d y\right|_{y=1}<0$, then the evolutionary stability strategy is $y=1$. When $I<C_{S}, d(F(y)) /\left.d y\right|_{y=1}<0$ is obtained, in which case $y=0$ is stable.

\section{Analysis on the Stability of Enterprises' Strategy} The expected return $u_{z}$ when enterprises choose the strategy of conducting green and low-carbon technology innovation, the expected return $u_{1-z}$ when enterprises adopt traditional technology, and the average expected return $\bar{u}_{3}$ are, respectively, shown as follows: 


$$
\begin{aligned}
u_{z}= & x y\left(R+\Delta R_{1}-C_{I}+\beta P+\gamma T-\lambda \alpha E\right) \\
& +x(1-y)\left(R+\Delta R_{2}-C_{I}+\beta P+\gamma T-\lambda \alpha E\right) \\
& +(1-x) y\left(R+\Delta R_{3}-C_{I}\right)+(1-x)(1-y)\left(R-C_{I}\right) \\
= & R-C_{I}+x y \Delta R_{1}+x(1-y) \Delta R_{2}+(1-x) y \Delta R_{3} \\
& +x(\beta P+\gamma T-\lambda \alpha E) \\
u_{1-z}= & x y\left(R-\alpha E-C_{L}\right)+x(1-y)(R-\alpha E) \\
& +(1-x) y\left(R-C_{L}\right)+(1-x)(1-y) R \\
= & R-x \alpha E-y C_{L} \\
\bar{u}_{3}= & z u_{z}+(1-z) u_{1-z} .
\end{aligned}
$$

Thus, the replicator dynamic equation of enterprises' choice of green and low-carbon technology innovation strategy is obtained, as shown in Eq. 9:

$$
\begin{aligned}
F(z)= & \frac{d z}{d t}=z\left(u_{z}-\bar{u}_{1}\right) \\
= & z(1-z)\left[x y\left(\Delta R_{1}-\Delta R_{2}-\Delta R_{3}\right)+x \Delta R_{2}+y \Delta R_{3}+x(\beta P\right. \\
& \left.+\gamma T-(\lambda+1) \alpha E)-C_{I}-y C_{L}\right] .
\end{aligned}
$$

Then, the first derivative of $\mathrm{F}(z)$ and defined $G(x, y)$ are, respectively, as shown in Eqs 10, 11:

$$
\begin{aligned}
\frac{d(F(z))}{d z}= & (1-2 z)\left[x y\left(\Delta R_{1}-\Delta R_{2}-\Delta R_{3}\right)+x \Delta R_{2}+y \Delta R_{3}\right. \\
& \left.+x(\beta P+\gamma T-(\lambda+1) \alpha E)-C_{I}-y C_{L}\right] \\
G(x, y) & =x y\left(\Delta R_{1}-\Delta R_{2}-\Delta R_{3}\right)+x \Delta R_{2}+y \Delta R_{3} \\
& +x(\beta P+\gamma T-(\lambda+1) \alpha E)-C_{I}-y C_{L}
\end{aligned}
$$

When condition $\mathrm{F}(z)=0$ and $d(F(z)) / d z<0$ are both met, enterprises' choice of green and low-carbon technology innovation strategy is in a stable state. Therefore, when $G(x, y)=0$, we have $\mathrm{F}(z)=0$ and $d(F(z)) / d z \equiv 0$, and all $z$ 's are in an evolutionarily stable state. When $G(x, y)>0$, we have $d(F(z)) /\left.d z\right|_{z=1}<0$, and thus, $z=1$ is an evolutionary stable strategy. When $G(x, y)<0, d(F(z)) /\left.d z\right|_{z=0}<0$ is derived. In this case, $z=0$ is the evolutionary stable strategy. Therefore, the evolutionary phase diagram of enterprises' adoption of green and low-carbon technology innovation is related to the quadratic curve $x y\left(\Delta R_{1}-\Delta R_{2}-\Delta R_{3}\right)+x \Delta R_{2}+y \Delta R_{3}+x(\beta P+\gamma T-(\lambda+1) \alpha E)-$ $C_{I}-y C_{L}$.

\section{Stability Analysis of Equilibrium Point of Tripartite Evolutionary Game System}

In the tripartite game between the government, the public, and enterprises, the replicator dynamics in Eqs 2, 6, 9 describe the dynamic process in which the bounded rational parties learn and adopt regulation strategies, supervision strategies, and green and low-carbon technology innovation strategies, respectively. When all the three parties reach a stable state, it means that all the players have found effective and stable Nash equilibrium solutions through continuous trial and error. In order to seek the equilibrium point of enterprises under environmental regulation, Equation set (12) is established as follows:

$$
\left\{\begin{aligned}
F(x)= & x\left(u_{x}-\bar{u}_{1}\right)=x(1-x)[\alpha E(1-z+z \lambda)+z(-\beta P-\gamma T)-\eta K]=0 \\
F(y)= & y\left(u_{y}-\bar{u}_{2}\right)=y(1-y)\left(I-C_{S}\right)=0 \\
F(z)= & z(1-z)\left[x y\left(\Delta R_{1}-\Delta R_{2}-\Delta R_{3}\right)+x \Delta R_{2}+y \Delta R_{3}\right. \\
& \left.+x(\beta P+\gamma T-(\lambda+1) \alpha E)-C_{I}-y C_{L}\right]=0 .
\end{aligned}\right.
$$

All the strategic equilibrium solutions of the evolutionary game model are obtained by solving equation set 12): $E_{1}(0,0,0), \quad E_{2}(0,1,0), \quad E_{3}(0,1,1), \quad E_{4}(0,0,1), \quad E_{5}(1,0,1)$, $E_{6}(1,0,0), \quad E_{7}(1,1,0), \quad E_{8}(1,1,1), \quad E_{9}\left(\frac{C_{I}}{\Delta R_{2}+\beta P+\gamma T-(\lambda+1) \alpha E}\right.$, $\left.0, \frac{\alpha E-\eta K}{(1-\lambda) \alpha E+\beta P+\gamma T}\right), \quad E_{10}\left(\frac{C_{I}+C_{L}-\Delta R_{3}}{\Delta R_{1}-\Delta R_{3}+\beta P+\gamma T-(\lambda+1) \alpha E}, 1, \frac{\alpha E-\eta K}{(1-\lambda) \alpha E+\beta P+\gamma T}\right)$. The Jacobian matrix of the tripartite evolutionary game system is given as follows:

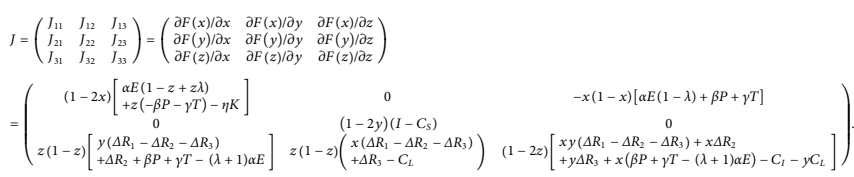

According to the Lyapunov equilibrium stability theory, when all eigenvalues of the Jacobian matrix are less than 0 , the equilibrium point is asymptotically stable. When all eigenvalues in the Jacobian matrix are greater than 0 , the equilibrium point is unstable. When the eigenvalues of the Jacobian matrix are both positive and negative, the equilibrium point is an unstable point. The Lyapunov indirect method was used to analyze the stability of each pure strategy equilibrium point, and the results are given in Table 3.

As can be seen from Table $3, E_{4}(0,0,1), E_{5}(1,0,1)$, and $E_{8}(1,1,1)$ are all unstable equilibrium solutions. When $C_{s}>I$, the system has at least one equilibrium point $E_{1}(0,0,0)$. And if $C_{s}>$ Iand $\alpha E<\eta K$ are both satisfied, the replication dynamic system has only one stable point $E_{1}(0,0,0)$. It shows that when the supervision cost of the public is greater than the supervision reward, and the pollution tax collected by the government is less than the expenditure on public propaganda and guidance, the government and the public will tend to adopt the strategy combination (no environmental regulation, no supervision). When $C_{L}+C_{I}<\Delta R_{3}, C_{s}<I$, there is at least one equilibrium point $E_{3}(0,1,1)$ in the system, that is, when the government and the public, respectively, adopt no regulation and supervision strategy, then enterprises can be effectively mobilized to conduct low-carbon technological innovation in the case that the benefits of conducting green and low-carbon technological innovation are greater than the sum of its possible costs, as can be seen from the stability condition of $E_{6}(1,0,0)$ and $E_{7}(1,1,0)$; when enterprises are faced with constraint conditions $\Delta R_{2}-C_{I}+$ $\beta P+\gamma T-(1+\lambda) \alpha E<0 \quad$ and $\Delta R_{1}-C_{I}-C_{L}+\beta P+\gamma T-(1+\lambda) \alpha E<0, \quad$ respectively, under the two strategy combinations (regulation, no supervision) and (regulation, supervision), it is a stable strategy for enterprises not to conduct green and low-carbon technology innovation.

\section{NUMERICAL SIMULATION ANALYSIS}

The asymptotic stability analysis of the evolutionary game shows that the stability of strategies of the government, the public, and 
TABLE 3 | Result of local Stability.

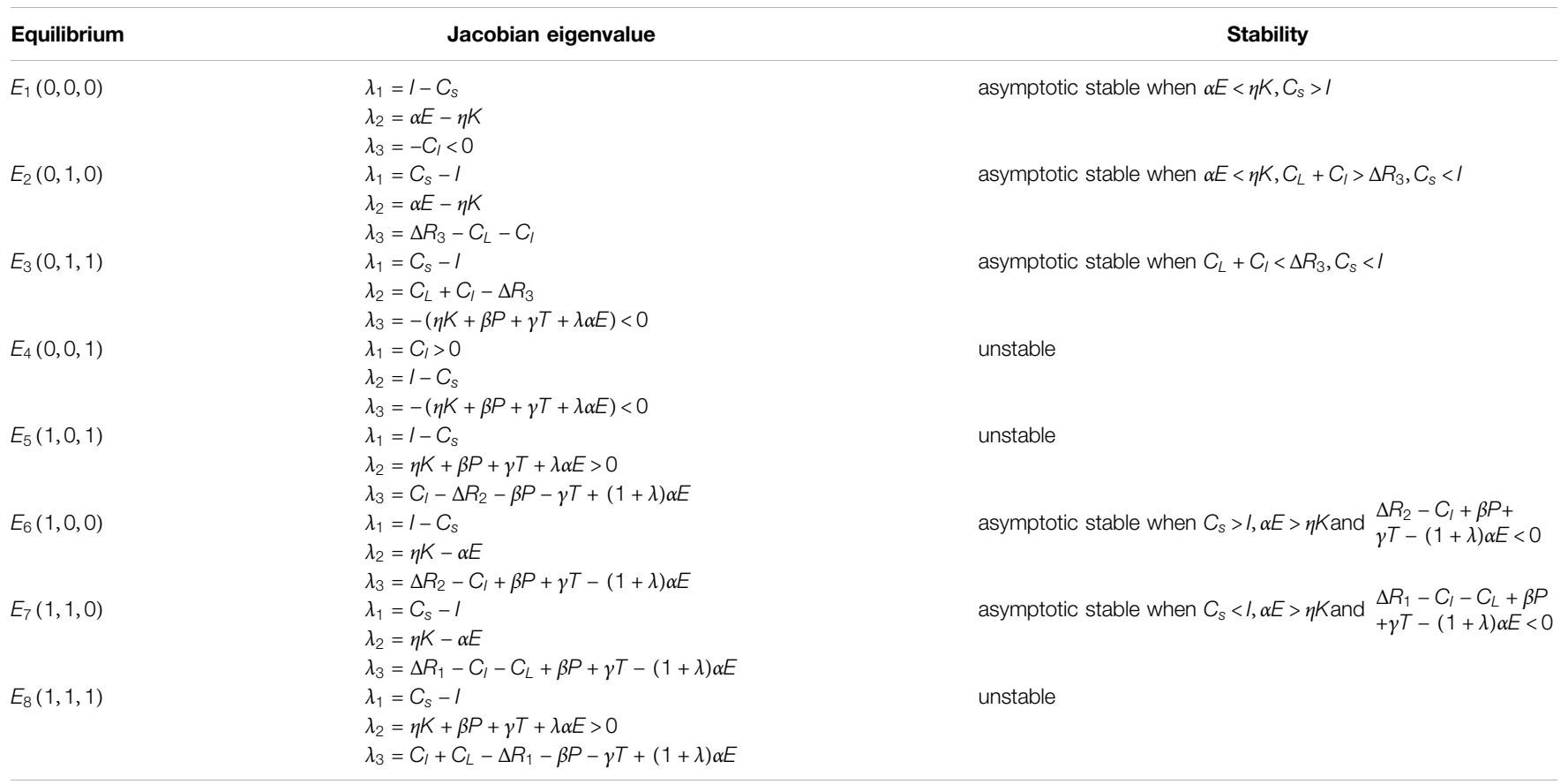

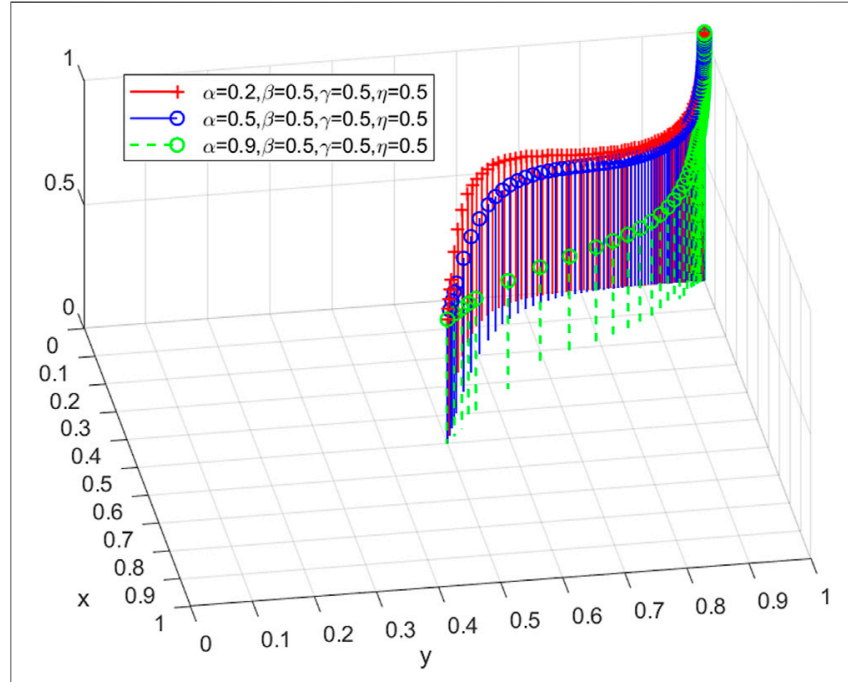

FIGURE 2 | System evolution trajectory under different tax intensities $\alpha$.

the enterprise are closely related to the benefits and costs of all parties. To visually depict the asymptotic stable operation track of enterprises' green technology innovation under different executive strengths of pollution tax, subsidies, propaganda, and guidance, respectively, this study uses a MATLAB simulation tool to conduct numerical simulation analysis on the aforementioned evolutionary game model. The initial value of the parameter is set as follows: $\lambda=0.5, \mathrm{C}_{S}=30, \mathrm{C}_{I}=50$, $\mathrm{C}_{L}=20, \Delta R_{1}=100, \Delta R_{2}=90, \Delta R_{3}=80, \quad \mathrm{I}=50, \quad \mathrm{P}=100$, $\mathrm{T}=100, \mathrm{~K}=100, \mathrm{E}=100$, which met the stability condition of $E_{3}(0,1,1)$.
The initial proportion of "regulation," "supervision," and "conduct green and low-carbon technology innovation" strategies chosen by the government, the public, and enterprises was set as $(0.5,0.5,0.5)$. The number of times that the dynamic equations evolve with time was set as 100 . The $x, y$, and $z$ axes in Figure 2-Figure 5 represent the probability of the government, public, and enterprises choosing environmental regulation, supervision, and conducting green low-carbon technology innovation, respectively.

First, the levy intensity of the pollution tax $\alpha$ is assigned 0.2 , 0.5 , and 0.9 , respectively, to analyze the impact of different pollution tax intensity on the process and results in evolutionary game. The simulation results are shown in Figure 2. From the evolutionary trajectory of Figure 2, it can be seen that the environmental regulation means of pollution tax on enterprises can effectively mobilize enterprises' low-carbon and green technological innovation. In the case of pollution tax levied by the government, enterprises will choose green and lowcarbon technological innovation after weighing the cost of pollution and technological innovation. The evolution speed of enterprises choosing green and low-carbon technology innovation is faster at a low intensity of pollution tax. Therefore, the levy of pollution tax has a certain incentive effect on enterprises' green and low-carbon technological innovation. And there may be an optimal value for the intensity of pollution tax. As can be seen from Figure 2, as the probability of the government choosing the environmental regulation strategy decreases, the public gradually plays a major supervisory role. Under the government's regulatory means of collecting pollution taxes, enterprises will abandon the traditional technology and choose to conduct green and low-carbon technology innovation. When enterprises constantly adjust 


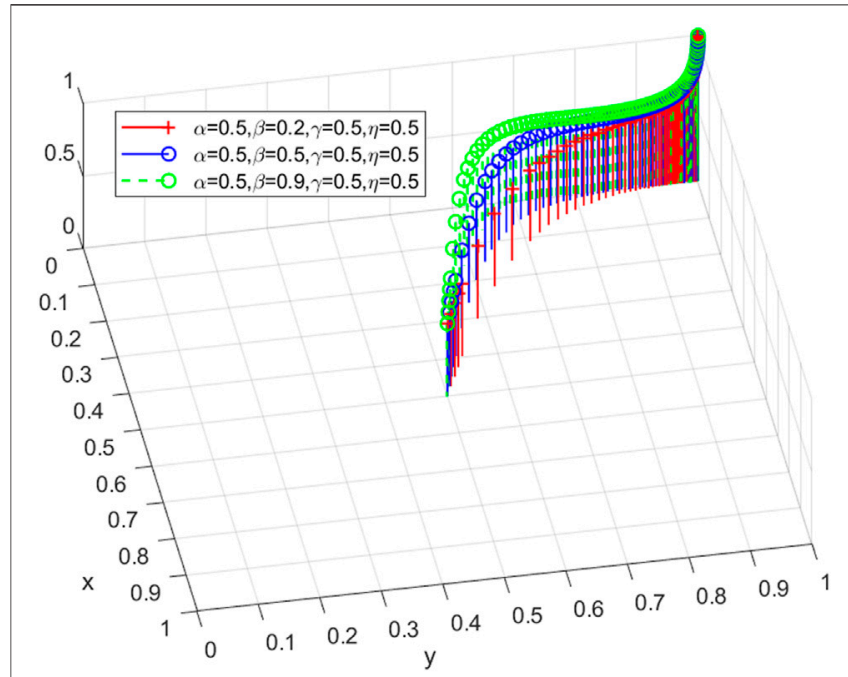

FIGURE 3 | System evolution trajectory under different subsidy intensities $\beta$.

their strategies, gradually reduce their dependence on the traditional technological innovation, and conduct green and low-carbon technological innovation consciously and spontaneously, the ecological environment will be improved. Then the government tends to cancel pollution tax gradually, where the supervision of the public will play a major role. Besides, with the strengthening of the government's pollution tax intensity, the public's supervision on enterprises' green and low-carbon technology innovation behavior will also be strengthened.

In order to explore the incentive effect of different intensities of innovation subsidies on enterprises' green and low-carbon technology innovation, we assign $0.2,0.5$, and 0.9 to the implementation intensity $\beta$ and $\gamma$ of subsidies for innovative product price and subsidies for innovation cost, respectively. The evolution path of the system under different intensities of innovation subsidies is shown in Figures 3, 4. With the increase in innovation subsidy intensity, enterprises are stable in green and low-carbon technology innovation strategy much faster, which indicates that subsidy incentive plays a significant role in promoting enterprises' green and low-carbon technology innovation. And the incentive effect of innovation subsidies on enterprises' green and low-carbon innovation is most significant at the intensity of 0.9 . However, under this intensity, the probability of the government adopting environmental regulation strategy evolves to 0 at the fastest rate. As a kind of cost compensation, low-carbon innovation subsidies reduce the cost of low-carbon technology innovation activities to a certain extent, largely alleviating the economic pressure and constraints faced by enterprises. However, the input of subsidy funds increases the financial burden, which increases the cost and pressure of environmental regulation for the government. And in reality, the government also needs to prevent some enterprises from cheating on subsidies, which also brings some difficulties to the implementation of innovation subsidies. With the incentive of subsidies, enterprises constantly adjust their production and operation activities. With the increasing knowledge and experience of green and low-carbon technology innovation, the cost of innovation will greatly decrease, and enterprises' willingness of low-carbon technology innovation will gradually strengthen. Thus, the proportion of enterprises adopting green and low-carbon technology innovation strategy will increase as time moving by. With the popularization and wide application of green and low-carbon technology, governments will gradually eliminate the innovation subsidies, so that the supervision of the public will play a leading role. Therefore, the government's innovation subsidies can effectively mobilize enterprises' green and low-carbon technological innovation. Moreover, innovation subsidies of high intensity have the most obvious incentive effect on enterprises' low-carbon technological innovation, as well as the strongest inhibitory effect on government's environmental regulation.

Numerical simulation analysis was carried out when the intensity of government's environmental propaganda and guidance to the public is $0.2,0.5$, and 0.9 , respectively. The evolution trajectory of the system is shown in Figure 5. With different intensities of environmental propaganda and guidance, the three parties, respectively, choose "no regulation," "supervision," "conduct green and low-carbon technology innovation" as the ultimate strategy, that is, because of the government's environmental protection, propaganda work successfully improved the public environmental protection consciousness and effectively motivated the social public supervision behavior of low-carbon production activities of the enterprise. The government will gradually loosen environmental regulations and let the public's supervision play a leading role. This is because the government's efforts on environmental propaganda and guidance have successfully raised the public's awareness of environmental protection and effectively encouraged the public to supervise enterprises' low-carbon

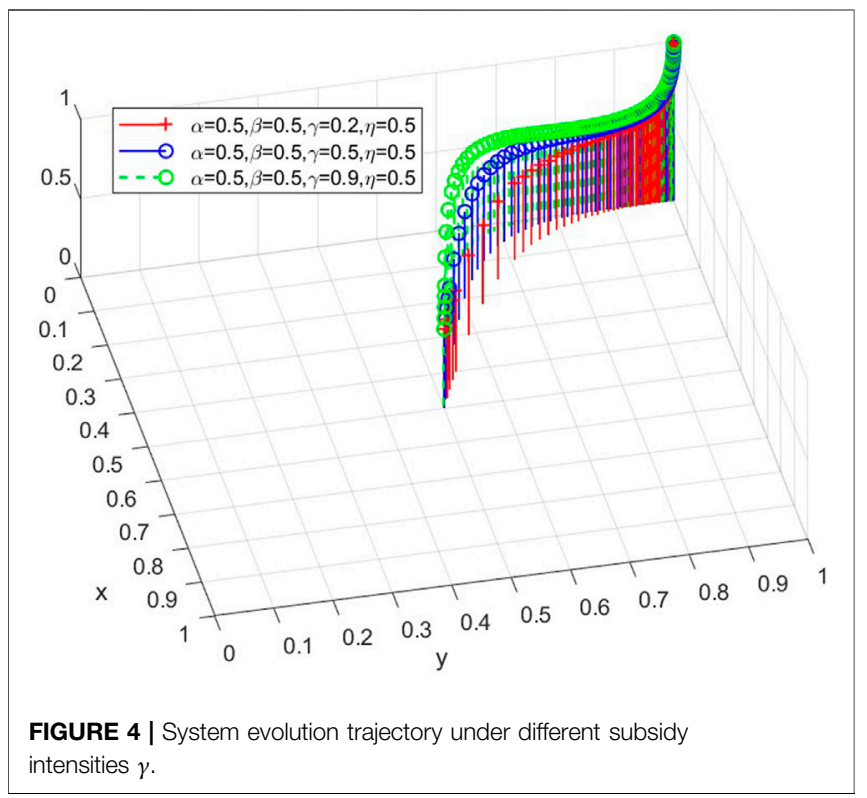




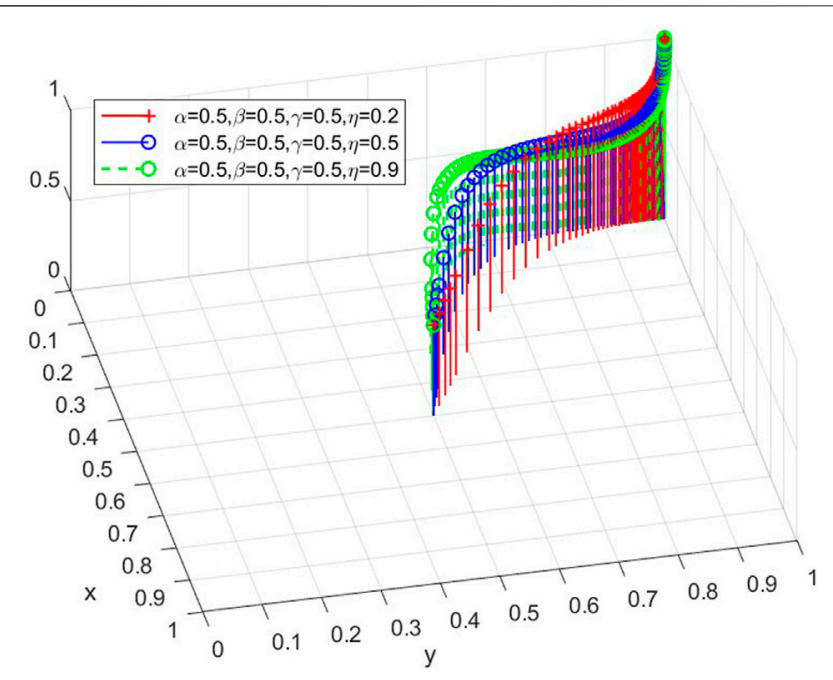

FIGURE 5 | System evolution trajectory under different propaganda and guidance efforts $\eta$.

production activities. Therefore, the government will gradually relax environmental regulations, making the supervision of the public play a leading role. In addition, it can be seen from Figure 5 that low intensity of public propaganda and guidance has the strongest incentive effect on enterprises' low-carbon technological innovation, that is, the proportion of enterprises choosing low-carbon technological innovation evolves to 1 at the fastest rate. However, the high-intensity public propaganda and guidance do not significantly accelerate enterprises' choice of green and low-carbon technology innovation, and the speed of public supervision evolved to a stable state in the high-intensity case is also slow. The government's environmental propaganda and guidance and the public's supervision all take costs. Besides, when enterprises conduct green and low-carbon technological innovation and related production activities, the innovation cost will be partially transferred to consumers. Therefore, with the strengthening of government's propaganda and guidance, the cost of the public and enterprises will be further increased, which will slow down the evolution speed of enterprises' green and lowcarbon technological innovation and the adoption of supervision behavior by the public. In addition, in the case of asymmetric information, excessive environmental publicity may also inhibit the public's preference for low-carbon products to a certain extent, thus having a negative impact on the enthusiasm of enterprises for green and low-carbon technology innovation.

\section{CONCLUSION}

Green and low-carbon technology innovation is the fundamental way to implement energy conservation and environmental protection and achieve low-carbon economy. As an important carrier of economic development, enterprises should undertake the responsibility and mission of developing low-carbon economy and actively conduct green and low-carbon technology innovation. The government and the public, as the main stakeholders of green and low-carbon technological innovation, should create favorable conditions for the lowcarbon development of enterprises and help enterprises overcome obstacles such as high cost and technical barriers, thus mobilizing enterprises to conduct green and low-carbon technological innovation. The synergy among the government, the public, and enterprises is the key to the development of lowcarbon economy in China.

Therefore, it is of great significance to study how should the government make effective environmental regulation policies to fully mobilize the enthusiasm of the public and enterprises, thus directly or indirectly stimulating enterprises' green and lowcarbon technological innovation. Different from some existing studies, this work not only focuses on the interaction between two of the government, public consumers, and enterprises but also studies the three in a unified system. Specifically, under the assumption of information asymmetry and bounded rationality, this study applies the evolutionary game method to study the incentive mechanism of enterprises' green and lowcarbon technological innovation. Specifically, this study constructs an evolutionary game model that includes the government, the public, and enterprises and obtains the evolutionary stability strategy by analyzing the replication dynamic equations of each subject. And the evolutionary path of the game under different enforcement efforts of environmental regulation means is numerically simulated. The results show that 1) the regulation means of pollution tax, subsidies for low-carbon technology innovation products and innovation costs, and environmental propaganda and guidance are all effective incentives for enterprises' green low-carbon technology innovation; 2) moderate pollution tax can effectively promote the green and low-carbon technology innovation of enterprises; 3) high innovation subsidies have a significant incentive effect on enterprises' innovation behavior of low-carbon technology; and 4) the incentive effect of low-intensity environmental propaganda and guidance on enterprises' green technology innovation is stronger than that of high intensity.

This study also has policy implications. Based on the aforementioned analysis, this study puts forward the following suggestions:

1) As the promoter of green and low-carbon technology innovation and the authority of social and environmental supervision, government's management means and management intensity will have an impact on enterprises' green technology innovation. Therefore, the government should reasonably choose the means and intensity of environmental regulation so as to prevent the implementation of excessive regulatory means from hindering the green and low-carbon technological innovation of enterprises, which poses a higher requirement for the government's incentive mechanism design. First of all, the traditional view of all enterprises as the same type of hybrid mechanism no longer meets the practical requirements. For different types of enterprises, the government should treat them differently according to their 
actual situation. A relatively fair mechanism can be formed by giving matching incentive intensity according to the different levels of low-carbon technology of enterprises. In this way, the motivation of enterprises to conduct green low-carbon technology innovation can be improved. Second, the government should reasonably determine the subsidy level, evaluate the efficiency of subsidy implementation in time, and dynamically adjust the subsidy level according to the evaluation results. Third, the government should dynamically adjust the level of pollution tax and timely evaluate the efficiency of different tax implementation so as to find the optimal proportion of pollution tax. In addition, the environmental propaganda and guidance of the public should not be neglected. As the main body of the market economy, the consumer's consumption preference is the production orientation of enterprises. The government can improve consumers' awareness of green and low-carbon products through low-carbon public service advertisements and other publicity methods and provide appropriate incentives for their green and low-carbon consumption. Last but not least, green-credit policy should also be committed to provide support for enterprises' green and low-carbon technological innovation. Moreover, the government should improve the certification standards of low-carbon product, establish market access systems, and improve the intellectual property protection laws for lowcarbon technology so as to create a good institutional environment for the development of green and low-carbon industries.

2) As the main demand body in goods market, the consumption behavior of the public has a significant impact on the production decision-making of enterprises. Therefore, the public consumers should first improve their awareness of low-carbon environmental protection and then cultivate the concept of low-carbon consumption in their daily life by collecting information about green and low-carbon products and services spontaneously, thus gradually increasing the cognition and demand for low-carbon products and services. Second, the public should be aware of their responsibilities as environmental stakeholders and take the initiative to play the role of the market regulator. In efforts to supervise enterprises' low-carbon production and operation activities and eliminate non-environmental protection products, the public can contribute a lot to the development of green and low-carbon technology innovation.

\section{REFERENCES}

Bi, K., Huang, P., and Wang, X. (2016). Innovation Performance and Influencing Factors of Low-Carbon Technological Innovation under the Global Value Chain: A Case of Chinese Manufacturing Industry. Technol. Forecast. Soc. Change 111, 275-284. doi:10.1016/ j.techfore.2016.07.024

Brav, A., Jiang, W., Ma, S., and Tian, X. (2018). How Does Hedge Fund Activism Reshape Corporate Innovation? J. Financial Econ. 130, 237-264. doi:10.1016/ j.jfineco.2018.06.012
3) It has become a global consensus to develop low-carbon economy. And low-carbon technological innovation has also become a worldwide trend. Enterprises should seize the opportunity and take the initiative to implement the strategy of green and low-carbon technology innovation. To be specific, enterprise should first strengthen their awareness of social responsibility and green environmental protection and take the initiative to conduct green and lowcarbon technological innovation. Besides, at the same time of increasing innovation investment, enterprises should also constantly improve the quality of their low-carbon products and strength to meet the production capacity and requirement of green and low-carbon technological innovation so as to occupy a favorable competitive position in the lowcarbon product market. Second, enterprises should develop a long-term low-carbon innovation strategy and improve their own low-carbon management mechanism, which contributes to reducing the cost of low-carbon production. At the same time, enterprises should also make full use of various incentive policies of the government, with the guidance of the government policy mechanism, promoting the low-carbon technology innovation process with maximum efficiency and achieving great progress and sustainable development of enterprises. Last but not least, enterprises can strengthen the publicity of the performance and long-term environmental advantages of low-carbon products so as to enhance consumers' cognition and trust on the performance of their products and thus attract more consumers with low-carbon preference.

\section{DATA AVAILABILITY STATEMENT}

The original contributions presented in the study are included in the article; further inquiries can be directed to the corresponding author.

\section{AUTHOR CONTRIBUTIONS}

LC and XB contributed to conceptualization, methodology, and writing-original draft; $\mathrm{BC}$ assisted with software, data curation, and writing-review and editing; JW helped with conceptualization, methodology, writing-review and editing, and supervision. All authors have read and agreed to the published version of the manuscript.

Brunnermeier, S. B., and Cohen, M. A. (2003). Determinants of Environmental Innovation in US Manufacturing Industries. J. Environ. Econ. Manag. 45, 278-293. doi:10.1016/S0095-0696(02)00058-X

Cao, C., Wu, X. B., Zhou, G. G., and Hu, Q. (2012). Game Analysis on Innovation and Diffusion of green Product Among Manufacturers. J. Syst. Eng. 27, 617-625.

Chakraborty, P., and Chatterjee, C. (2017). Does Environmental Regulation Indirectly Induce Upstream Innovation? New Evidence from India. Res. Pol. 46, 939-955. doi:10.1016/j.respol.2017.03.004

Chang, Y., and Zhang, T. (2019). The Effects of Product Consistency and Consumer Resistance to Innovation on Green Product Diffusion in China. Sustainability 11 (9), 2702. doi:10.3390/su11092702 
Chen, C.-C., Chen, C.-W., and Tung, Y.-C. (2018). Exploring the Consumer Behavior of Intention to purchase green Products in Belt and Road Countries: An Empirical Analysis. Sustainability 10, 854. doi:10.3390/ su 10030854

Chen, W., and Hu, Z.-H. (2018). Using Evolutionary Game Theory to Study Governments and Manufacturers' Behavioral Strategies under Various Carbon Taxes and Subsidies. J. Clean. Prod. 201, 123-141. doi:10.1016/ j.jclepro.2018.08.007

Cheng, S., Chen, Y., Meng, F., Chen, J., Liu, G., and Song, M. (2021). Impacts of Local Public Expenditure on CO2 Emissions in Chinese Cities: A Spatial Cluster Decomposition Analysis. Resour. Conservation Recycling 164, 105217. doi:10.1016/j.resconrec.2020.105217

Cheng, Y., and Yao, X. (2021). Carbon Intensity Reduction Assessment of Renewable Energy Technology Innovation in China: A Panel Data Model with Cross-Section Dependence and Slope Heterogeneity. Renew. Sust. Energ. Rev. 135, 110157. doi:10.1016/j.rser.2020.110157

Cheng, Z., Li, L., and Liu, J. (2017). The Emissions Reduction Effect and Technical Progress Effect of Environmental Regulation Policy Tools. J. Clean. Prod. 149, 191-205. doi:10.1016/j.jclepro.2017.02.105

Chintrakarn, P. (2008). Environmental Regulation and U.S. States' Technical Inefficiency. Econ. Lett. 100, 363-365. doi:10.1016/j.econlet.2008.02.030

Dietrich, U., and Chen, H.-H. (2018). Towards Carbon Free Cities: Interplay between Urban Density and Energy Demand. Int. J. SDP 13, 967-974. doi:10.2495/SDP-V13-N7-967-974

Du, K., Cheng, Y., and Yao, X. (2021). Environmental Regulation, green Technology Innovation, and Industrial Structure Upgrading: The Road to the green Transformation of Chinese Cities. Energ. Econ. 98, 105247. doi:10.1016/j.eneco.2021.105247

Fan, R., and Dong, L. (2018). The Dynamic Analysis and Simulation of Government Subsidy Strategies in Low-Carbon Diffusion Considering the Behavior of Heterogeneous Agents. Energy Policy 117, 252-262. doi:10.1016/ j.enpol.2017.12.003

Fan, R., Dong, L., Yang, W., and Sun, J. (2017). Study on the Optimal Supervision Strategy of Government Low-Carbon Subsidy and the Corresponding Efficiency and Stability in the Small-World Network Context. J. Clean. Prod. 168, 536-550. doi:10.1016/j.jclepro.2017.09.044

Fan, R., Lin, J., and Zhu, K. (2019). Study of Game Models and the Complex Dynamics of a Low-Carbon Supply Chain with an Altruistic Retailer under Consumers' Low-Carbon Preference. Physica A: Stat. Mech. its Appl. 528, 121460. doi:10.1016/j.physa.2019.121460

Friedman, D. (1998). On Economic Applications of Evolutionary Game Theory. J. Evol. Econ. 8, 15-43. doi:10.1007/s001910050054

Gaffney, O., and Steffen, W. (2017). The Anthropocene Equation. Anthropocene Rev. 4, 53-61. doi:10.1177/2053019616688022

Guo, Q., Zhou, M., Liu, N., and Wang, Y. (2019). Spatial Effects of Environmental Regulation and green Credits on green Technology Innovation under LowCarbon Economy Background Conditions. Ijerph 16, 3027. doi:10.3390/ ijerph 16173027

Hofbauer, J., and Sandholm, W. H. (2007). Evolution in Games with Randomly Disturbed Payoffs. J. Econ. Theor. 132, 47-69. doi:10.1016/j.jet.2005.05.011

Hu, A. G., Zheng, J., Gao, Y., Zhang, N., and Xu, H. P. (2008). Provincial Technology Efficiency Ranking with Environment Factors (1999-2005). China Econ. Q. 7 (3), 933-960. (In Chinese).

Huang, J., Leng, M., Liang, L., and Liu, J. (2013). Promoting Electric Automobiles: Supply Chain Analysis under a Government's Subsidy Incentive Scheme. IIE Trans. 45, 826-844. doi:10.1080/0740817X.2012.763003

Jan, I. U., Ji, S., and Yeo, C. (2019). Values and Green Product Purchase Behavior: The Moderating Effects of the Role of Government and Media Exposure. Sustainability 11 (23), 6642. doi:10.3390/su11236642

Jia, P., Li, K., and Shao, S. (2018). Choice of Technological Change for China's LowCarbon Development: Evidence from Three Urban Agglomerations. J. Environ. Manage. 206, 1308-1319. doi:10.1016/j.jenvman.2017.08.052

Jiang, X. L., Dai, W. W., and Luo, P. F. (2018). Research on Promotion Mechanism of Manufacturing Enterprises' Ecological Innovation. Ecol. Econ. (Ecological Economy) 34 (8), 64-69.

Jiao, J., Chen, J., Li, L., and Li, F. (2017). A Study of Local Governments' and Enterprises' Actions in the Carbon Emission Mechanism of Subsidy or Punishment Based on the Evolutionary Game. Chin. J. Manag. Sci. 25, 140-150.
Kammerer, D. (2009). The Effects of Customer Benefit and Regulation on Environmental Product Innovation. Ecol. Econ. 68, 2285-2295. doi:10.1016/ j.ecolecon.2009.02.016

Khan, S. A. R., Yu, Z., and Umar, M. (2021). How Environmental Awareness and Corporate Social Responsibility Practices Benefit the enterprise? an Empirical Study in the Context of Emerging Economy. Meq 32 (5), 863-885. doi:10.1108/ MEQ-08-2020-0178

Klassen, R. D., and McLaughlin, C. P. (1996). The Impact of Environmental Management on Firm Performance. Manag. Sci. 42, 1199-1214. doi:10.1287/ mnsc.42.8.1199

Krass, D., Nedorezov, T., and Ovchinnikov, A. (2013). Environmental Taxes and the Choice of green Technology. Prod. Oper. Manag. 22, a-n. doi:10.1111/ poms. 12023

Lai, X., Liu, J., and Georgiev, G. (2016). Low Carbon Technology Integration Innovation Assessment index Review Based on Rough Set Theory - an Evidence from Construction Industry in China. J. Clean. Prod. 126, 88-96. doi:10.1016/ j.jclepro.2016.03.035

Li, F., Xu, X., Li, Z., Du, P., and Ye, J. (2021). Can Low-Carbon Technological Innovation Truly Improve enterprise Performance? the Case of Chinese Manufacturing Companies. J. Clean. Prod. 293, 125949. doi:10.1016/ j.jclepro.2021.125949

Liang, Z., Hewitt, R. R., and Du, Y. (2019). Research on Design Method for the Blue-Green Ecological Network System to deal with Urban Flooding: A Case Study of Charleston peninsula. Int. J. DNE 14, 275-286. doi:10.2495/DNE-V14N4-275-286

Lin, B., and Zhu, J. (2019). Determinants of Renewable Energy Technological Innovation in China under CO2 Emissions Constraint. J. Environ. Manage. 247, 662-671. doi:10.1016/j.jenvman.2019.06.121

Lin, R.-J., Tan, K.-H., and Geng, Y. (2013). Market Demand, green Product Innovation, and Firm Performance: Evidence from Vietnam Motorcycle Industry. J. Clean. Prod. 40, 101-107. doi:10.1016/j.jclepro.2012.01.001

Liu, C., Huang, W., and Yang, C. (2017). The Evolutionary Dynamics of China's Electric Vehicle Industry - Taxes vs. Subsidies. Comput. Ind. Eng. 113, 103-122. doi:10.1016/j.cie.2017.08.026

Lutz, C., Meyer, B., Nathani, C., and Schleich, J. (2005). Endogenous Technological Change and Emissions: The Case of the German Steel Industry. Energy Policy 33, 1143-1154. doi:10.1016/j.enpol.2003.11.012

Lyu, X., Shi, A., and Wang, X. (2020). Research on the Impact of Carbon Emission Trading System on Low-Carbon Technology Innovation. Carbon Manag. 11, 183-193. doi:10.1080/17583004.2020.1721977

Ma, J., and Sun, L. (2018). Complexity Analysis about Nonlinear Mixed Oligopolies Game Based on Production Cooperation. IEEE Trans. Contr. Syst. Technol. 26, 1532-1539. doi:10.1109/TCST.2017.2702120

Mahmoudi, R., and Rasti-Barzoki, M. (2018). Sustainable Supply Chains under Government Intervention with a Real-World Case Study: An Evolutionary Game Theoretic Approach. Comput. Ind. Eng. 116, 130-143. doi:10.1016/ j.cie.2017.12.028

Miao, Z., Baležentis, T., Tian, Z., Shao, S., Geng, Y., and Wu, R. (2019). Environmental Performance and Regulation Effect of China's Atmospheric Pollutant Emissions: Evidence from "Three Regions and Ten Urban Agglomerations". Environ. Resource Econ. 74, 211-242. doi:10.1007/s10640-018-00315-6

Minghua, L., and Yongzhong, Y. (2011). Environmental Regulation and Technology Innovation: Evidence from China. Energ. Proced. 5, 572-576. doi:10.1016/j.egypro.2011.03.100

Olusegun, A. H., Hasbullah, A., and Nordin, N. (2014). Influence of Top Management Commitment, Stakeholder Pressure and Public Concern on Sustainable Environmental Manufacturing Practices in Malaysia: Data Screening and Preliminary Analysis. Int. J. Bus. Manag. 2, 189.

Ouyang, X., Li, Q., and Du, K. (2020). How Does Environmental Regulation Promote Technological Innovations in the Industrial Sector? Evidence from Chinese Provincial Panel Data. Energy Policy 139, 111310. doi:10.1016/ j.enpol.2020.111310

Pan, X., Cao, Y., Pan, X., and Uddin, M. K. (2021). The Cleaner Production Technology Innovation Effect of Environmental Regulation Policy: Evidence from China. Meq 32 (4), 737-751. doi:10.1108/MEQ-10-2020-0227

Qu, X., Li, C., Dai, Y., and Li, C. (2019). Semiempirical Backscatter Models at Low Incidence Angles under Rain Conditions. J. Appl. Rem. Sens. 13, 1. doi:10.1117/ 1.jrs.13.048507 
Smith, J. M. (1976). Evolution and the Theory of Games. Am. Sci. 64 (1), 41-45. Smulders, S., Toman, M., and Withagen, C. (2014). Growth Theory and 'green Growth'. Oxford Rev. Econ. Pol. 30, 423-446. doi:10.1093/oxrep/gru027

Song, M., Wang, S., and Zhang, H. (2020a). Could Environmental Regulation and R\&D Tax Incentives Affect green Product Innovation? J. Clean. Prod. 258, 120849. doi:10.1016/j.jclepro.2020.120849

Song, M., Xie, Q., and Shen, Z. (2021). Impact of green Credit on High-Efficiency Utilization of Energy in China Considering Environmental Constraints. Energy Policy 153, 112267. doi:10.1016/j.enpol.2021.112267

Song, M., Zhao, X., and Shang, Y. (2020b). The Impact of Low-Carbon City Construction on Ecological Efficiency: Empirical Evidence from Quasi-Natural Experiments. Resour. Conservation Recycling 157, 104777. doi:10.1016/ j.resconrec.2020.104777

Su, X., Duan, S., Guo, S., and Liu, H. (2018a). Evolutionary Games in the Agricultural Product Quality and Safety Information System: A Multiagent Simulation Approach. Complexity 2018, 1-13. doi:10.1155/2018/7684185

Su, X., Liu, H., and Hou, S. (2018b). The Trilateral Evolutionary Game of AgriFood Quality in Farmer-Supermarket Direct Purchase: A Simulation Approach. Complexity 2018, 1-11. doi:10.1155/2018/5185497

Teixidó, J., Verde, S. F., and Nicolli, F. (2019). The Impact of the EU Emissions Trading System on Low-Carbon Technological Change: The Empirical Evidence. Ecol. Econ. 164, 106347. doi:10.1016/ j.ecolecon.2019.06.002

Tian, X., Bai, F., Jia, J., Liu, Y., and Shi, F. (2019). Realizing Low-Carbon Development in a Developing and Industrializing Region: Impacts of Industrial Structure Change on $\mathrm{CO} 2$ Emissions in Southwest China. J. Environ. Manage. 233, 728-738. doi:10.1016/j.jenvman.2018.11.078

Wang, H., Cai, L., and Zeng, W. (2011). Research on the Evolutionary Game of Environmental Pollution in System Dynamics Model. J. Exp. Theor. Artif. Intelligence 23, 39-50. doi:10.1080/0952813X.2010.506300

Wang, L., and Zheng, J. (2019). Research on Low-Carbon Diffusion Considering the Game Among Enterprises in the Complex Network Context. J. Clean. Prod. 210, 1-11. doi:10.1016/j.jclepro.2018.10.297

Wu, B., Liu, P., and Xu, X. (2017). An Evolutionary Analysis of Low-Carbon Strategies Based on the Government-enterprise Game in the Complex Network Context. J. Clean. Prod. 141, 168-179. doi:10.1016/j.jclepro.2016.09.053

Wu, L., Kaneko, S., and Matsuoka, S. (2005). Driving Forces behind the Stagnancy of China's Energy-Related CO2 Emissions from 1996 to 1999: the Relative Importance of Structural Change, Intensity Change and Scale Change. Energy Policy 33, 319-335. doi:10.1016/j.enpol.2003.08.003

Xia, D., Chen, B., and Zheng, Z. (2015). Relationships Among Circumstance Pressure, green Technology Selection and Firm Performance. J. Clean. Prod. 106, 487-496. doi:10.1016/j.jclepro.2014.11.081
Xie, L., Ma, J., and Han, H. (2018). Implications of Stochastic Demand and Manufacturers' Operational Mode on Retailer's Mixed Bundling Strategy and its Complexity Analysis. Appl. Math. Model. 55, 484-501. doi:10.1016/ j.apm.2017.06.005

$\mathrm{Xu}$, J., and Lv, X. (2014). Evolutionary Analysis between Governments, Manufacting Enterprises and Consumers on Low-Carbon Decision-Making Behavior under the Background of Low-Carbon Economy. Oper. Res. Manag. Sci. 23, 81-91.

Zhang, L., Xue, L., and Zhou, Y. (2019a). How Do Low-Carbon Policies Promote green Diffusion Among alliance-based Firms in China? an Evolutionary-Game Model of Complex Networks. J. Clean. Prod. 210, 518-529. doi:10.1016/ j.jclepro.2018.11.028

Zhang, Q., He, K., and Huo, H. (2012). Cleaning China's Air. Nature 484, 161-162. doi: $10.1038 / 484161$ a

Zhang, Y., Ao, J., and Deng, J. (2019b). The Influence of High-Low Power on Green Consumption: The Moderating Effect of Impression Management Motivation. Sustainability 11 (16), 4287. doi:10.3390/su11164287

Zhang, Y., and Zhang, J. (2019). Estimating the Impacts of Emissions Trading Scheme on Low-Carbon Development. J. Clean. Prod. 238, 117913. doi:10.1016/ j.jclepro.2019.117913

Zhu, Q., Li, Y., Geng, Y., and Qi, Y. (2013). Green Food Consumption Intention, Behaviors and Influencing Factors Among Chinese Consumers. Food Qual. Preference 28, 279-286. doi:10.1016/j.foodqual.2012.10.005

Zhuge, L., Freeman, R. B., and Higgins, M. T. (2020). Regulation and Innovation: Examining Outcomes in Chinese Pollution Control Policy Areas. Econ. Model. 89, 19-31. doi:10.1016/j.econmod.2019.09.041

Conflict of Interest: The authors LC, XB, BC, and JW were employed by Chongqingfuling Electric Power Industrial Co., Ltd.

Publisher's Note: All claims expressed in this article are solely those of the authors and do not necessarily represent those of their affiliated organizations, or those of the publisher, the editors, and the reviewers. Any product that may be evaluated in this article, or claim that may be made by its manufacturer, is not guaranteed or endorsed by the publisher.

Copyright (c) 2022 Chen, Bai, Chen and Wang. This is an open-access article distributed under the terms of the Creative Commons Attribution License (CC BY). The use, distribution or reproduction in other forums is permitted, provided the original author(s) and the copyright owner(s) are credited and that the original publication in this journal is cited, in accordance with accepted academic practice. No use, distribution or reproduction is permitted which does not comply with these terms. 